\title{
Modelling atmospheric transport of $\alpha$-hexachlorocyclohexane in the Northern Hemisphere with a 3-D dynamical model: DEHM-POP
}

\author{
K. M. Hansen, J. H. Christensen, J. Brandt, L. M. Frohn, and C. Geels \\ Department of Atmospheric Environment, National Environmental Research Institute, Roskilde, Denmark
}

Received: 5 February 2004 - Published in Atmos. Chem. Phys. Discuss.: 8 March 2004

Revised: 30 June 2004 - Accepted: 2 July 2004 - Published: 13 July 2004

\begin{abstract}
The Danish Eulerian Hemispheric Model (DEHM) is a 3-D dynamical atmospheric transport model originally developed to describe the atmospheric transport of sulphur into the Arctic. A new version of the model, DEHMPOP, developed to study the atmospheric transport and environmental fate of persistent organic pollutants (POPs) is presented. During environmental cycling, POPs can be deposited and re-emitted several times before reaching a final destination. A description of the exchange processes between the land/ocean surfaces and the atmosphere is included in the model to account for this multi-hop transport. The $\alpha$-isomer of the pesticide hexachlorocyclohexane $(\alpha-\mathrm{HCH})$ is used as tracer in the model development. The structure of the model and processes included are described in detail. The results from a model simulation showing the atmospheric transport for the years 1991 to 1998 are presented and evaluated against measurements. The annual averaged atmospheric concentration of $\alpha-\mathrm{HCH}$ for the 1990s is well described by the model; however, the shorter-term average concentration for most of the stations is not well captured. This indicates that the present simple surface description needs to be refined to get a better description of the air-surface exchange processes of POPs.
\end{abstract}

\section{Introduction}

The term persistent organic pollutants (POPs) is used to describe a group of chemical compounds with different origins but common characteristics: semi-volatility, hydrophobicity, bioaccumulation, toxicity and great persistence in the environment (Jones and de Voogt, 1999). POPs are measured in all environmental media and in remote areas with no usage or direct emissions of the compounds (AMAP, 1998).

Correspondence to: K. M. Hansen

(kmh@dmu.dk)
The environmental fate of POPs is determined by environmental conditions such as temperature and soil organic carbon content and by key physical-chemical properties of the compounds, such as the aqueous solubility, the vapour pressure, and the partitioning coefficient between air and water (the Henry's law constant), octanol and water, and octanol and air, where octanol is used as a surrogate for the solid state (Jones and de Voogt, 1999).

POPs have a potential for long-range transport through the atmosphere because they are semi-volatile. The volatility is temperature dependent and POPs show a tendency to accumulate in cold regions, a process named cold condensation (Wania and Mackay, 1993). POPs can also be re-emitted to the atmosphere after deposition to the surface due to the temperature dependent volatility. In this way POPs can undergo several cycles of deposition and re-emission before reaching their final destination, a process named grasshopper or multihop transport (Wania and Mackay, 1996).

POPs may have adverse health effects on humans and wildlife: harmful effects on the immune and reproductive systems, and carcinogenic effects (Jones and de Voogt, 1999). POPs are hydrophobic; they bioaccumulate and magnify through the food chain (Jones and de Voogt, 1999). This raises concern especially for the top-predator species due to the harmful effects.

Several of the POPs are now banned or regulated through international treaties but they are still found in the Arctic environment (AMAP, 1998). The most important pathways of POPs to the Arctic environment are the atmosphere, the ocean and the fresh water system (AMAP, 1998). The atmosphere constitutes the most rapid of these pathways; therefore the atmospheric concentration and transport are key factors in the study of the Arctic environmental fate of POPs.

Concentrations of POPs in the environment are generally small and large samples are required to quantify them. The result is a low spatial and temporal resolution of the available measurements. Beside measurements, the environmental 


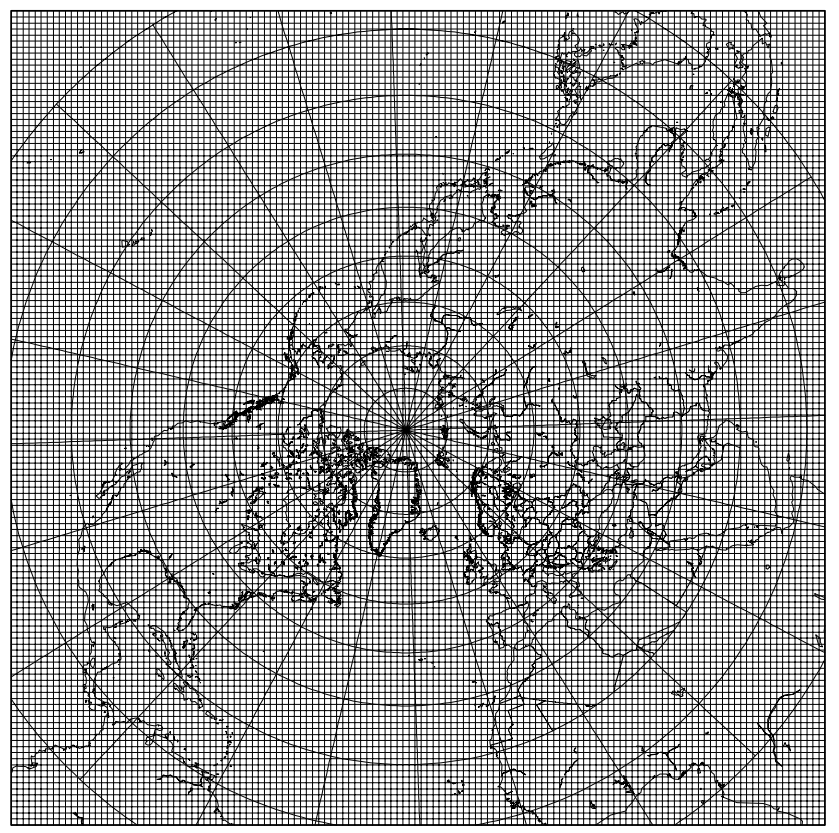

Fig. 1. The DEHM-POP model domain and horizontal grid: A polar stereographic projection with a resolution of $150 \mathrm{~km} \times 150 \mathrm{~km}$ at $60^{\circ} \mathrm{N}$.

fate of POPs can be estimated using different types of models. Multimedia compartment models have been used to evaluate the environmental fate of POPs on different scales with good results (e.g. Strand and Hov, 1996; Wania et al., 1999; Scheringer at al., 2000; MacLoed et al., 2001; Breivik and Wainia, 2002; Prevedouros et al., 2004; Toose et al., 2004). These models have generally very low spatial resolution with the whole globe or a confined region divided into few climate zones with a compartment for each of the environmental compartments described in each zone of the model. Information on size and extension of each compartment and exchange between climate zones and between environmental compartments is inferred from geographical reference databases and climatic averages of meteorological data. This type of model can be run in steady state mode to evaluate the environmental partitioning of POPs, or in dynamic mode to simulate the environmental fate of a compound over a longer period. However, to evaluate the spatial and temporal distribution of a compound in a certain area in detail, dynamical 3-D models must be used. Several models have been developed to describe the atmospheric transport of POPs on both regional (e.g. van Jaarsveld et al., 1997; Ma et al., 2003), hemispheric (Malanichev et al., 2004) and global scales (Koziol and Pudykiewicz, 2001).

The aim of this study is to present a high-resolution 3-D dynamical model, DEHM-POP, describing the atmospheric transport and environmental fate of POPs within the Northern Hemisphere with special focus on the transport into the Arctic. DEHM-POP has a higher spatial resolution and is used to simulate the atmospheric transport of POPs over a longer period than previous models with comparable domain size.

\section{Model description}

DEHM-POP is developed based on the Danish Eulerian Hemispheric Model (DEHM): a 3-D Eulerian dynamical atmospheric transport model. DEHM was originally developed to study the atmospheric transport of sulphur into the Arctic (Christensen, 1997). DEHM has also been expanded to study the atmospheric transport of lead (Christensen, 1999), $\mathrm{CO}_{2}$ (Geels et al., 2004) and a chemical scheme with 60 components (Frohn et al., 2002); it has been validated thoroughly for these compounds. In the horizontal the model is defined on a regular grid using a polar-stereographic projection with a resolution of $150 \mathrm{~km} \times 150 \mathrm{~km}$ at $60^{\circ} \mathrm{N}$. The DEHM-POP domain was enlarged from $96 \times 96$ grid cells in the horizontal in the earlier versions of DEHM to $135 \times 135$ grid cells and it now extends into the Southern Hemisphere (Fig. 1). There are 20 unevenly distributed vertical layers discretized using terrain-following $\sigma$-coordinates extending to a height of approximately $18 \mathrm{~km}$ with the highest resolution near the surface.

The model is based on the continuity equation:

$$
\begin{aligned}
\frac{\partial q}{\partial t}= & -\left(u \frac{\partial q}{\partial x}+v \frac{\partial q}{\partial y}+\dot{\sigma} \frac{\partial q}{\partial \sigma}\right) \\
& +K_{x} \frac{\partial^{2} q}{\partial x^{2}}+K_{y} \frac{\partial^{2} q}{\partial y^{2}}+\frac{\partial}{\partial \sigma}\left(K_{\sigma} \frac{\partial q}{\partial \sigma}\right) \\
& +P(t, x, y, \sigma, q)-Q(t, x, y, \sigma, q),
\end{aligned}
$$

where $q$ is the mixing ratio of the modelled compound, $t$ is time, $x, y$, and $\sigma$ are the horizontal and vertical coordinates, $u$ and $v$ are the components of the horizontal wind field and $\dot{\sigma}$ is the generalised vertical velocity, $K_{x}, K_{y}$, and $K_{\sigma}$ are the horizontal and vertical diffusion coefficients, and $P$ and $Q$ are sources and sinks.

Time integration of the continuity equation is done by splitting it into five sub-models, which are then solved successively in each time step. The first sub-model is the threedimensional advection, sub-models two to four are diffusion in the three dimensions and the fifth sub-model is sources and sinks including the special air-surface exchange processes for POPs. The first four sub-models are unchanged from previous versions of DEHM and they are thoroughly described by Christensen (1997) and Frohn et al. (2002). The fifth submodel is described in detail in the following subsections.

The time step is calculated using a Courant-FriedrichLevy stability criterion on the basis of the horizontal and vertical wind fields and the horizontal boundary conditions are non-periodic (Frohn et al., 2002). The boundary conditions are free at the top of the domain (Christensen, 1997), and are given by the air-surface exchange fluxes at the ground. 


\subsection{The modelled compound}

DEHM-POP is developed using the $\alpha$-isomer of the insecticide hexachlorocyclohexane $(\mathrm{HCH})$ as tracer. $\alpha-\mathrm{HCH}$ is the most abundant POP measured in air, water and snow in the Arctic (AMAP, 1998). HCH is used worldwide in two different formulations: Technical HCH and Lindane. Technical $\mathrm{HCH}$ contains five stable isomers. Percentages of isomers in the mixture are typically: $\alpha: 60-70 \%, \beta: 10-12 \%, \gamma$ : $6-10 \%, \delta: 3-4 \%, \epsilon: 3-4 \%$ depending on the manufacturer (Willett et al., 1998). Lindane is a refined product containing almost pure $\gamma-\mathrm{HCH}$, the isomer that exhibits the highest insecticidal activity (Willett et al., 1998).

Technical HCH is historically the most used insecticide worldwide (Li et al., 2000). A total usage of 9.4 million tonnes between 1948 and 1997 with maximum usage around 1980 has been estimated (Li et al., 2003). Technical HCH is banned in most countries and only small amounts are used worldwide, primarily for vector control. Lindane is still in use as seed treatment in some countries, but is banned in others ( $\mathrm{Li}, 1999)$. $\alpha-\mathrm{HCH}$ primarily affects the central nervous system and also promotes tumours (Willett et al., 1998).

$\alpha-\mathrm{HCH}$ is one of the most volatile POPs with a high vapour pressure. It also partitions more readily into water than into solid phase (particles and soil) with high water-air partitioning coefficient and low octanol-air partitioning coefficient. Measurements at the Canadian station Alert in the high Arctic have shown that even at temperatures of $-40^{\circ} \mathrm{C}$ the average fraction sorbed on particles is less than $1 \%$ of the measured gas-phase fraction (Halsall et al., 1998). Therefore the particle-bound fraction of $\alpha-\mathrm{HCH}$ can be disregarded and $\alpha-\mathrm{HCH}$ is modelled as a pure gas-phase chemical in DEHMPOP.

\subsection{Atmospheric sources and sinks}

The change in $\alpha-\mathrm{HCH}$ concentration, $C_{a}$, in the atmospheric layers with time is described in the model by:

$\frac{\partial C_{a}}{\partial t}=\frac{1}{z_{a}}\left(F_{\mathrm{emis}}-F_{\mathrm{exc}, \mathrm{s}}\right)-\lambda C_{a}-k_{\mathrm{air}} C_{a}$,

where $z_{a}$ is the thickness of the layer, $F_{\text {emis }}$ is the emission, described in Sect. 2.4.2, $F_{\text {exc,s }}$ is the air-surface gas exchange flux, which is zero for all layers but the lowermost, described in Sects. 2.3.1 and 2.3.2, $\lambda$ is the wet deposition scavenging coefficient, described in Sect. 2.2.1, and $k_{\text {air }}$ is the chemical transformation rate in air, described in Sect. 2.2.2.

\subsubsection{Wet deposition}

Wet deposition of $\alpha-\mathrm{HCH}$ is calculated in DEHM-POP $\mathrm{u}-$ sing a simple parameterisation based on a scavenging coefficient formulation as in earlier versions of DEHM (Christensen, 1997). The scavenging coefficients used in the model
Table 1. Values of soil and chemical properties used in DEHMPOP, as suggested by Jury et al. (1983).

\begin{tabular}{llll}
\hline Parameter & Symbol & Units & Value \\
\hline Soil depth & $z_{s}$ & $\mathrm{~m}$ & 0.15 \\
Water content & $l$ & $\mathrm{~m}^{3} \mathrm{~m}^{-3}$ & 0.3 \\
Air content & $a$ & $\mathrm{~m}^{3} \mathrm{~m}^{-3}$ & 0.2 \\
Bulk density & $\rho_{s}$ & $\mathrm{kgm}^{-3}$ & 1350 \\
Organic carbon fraction & $f_{\text {oc }}$ & $\mathrm{kgkg}^{-1}$ & 0.0125 \\
Air diffusion coefficient & $D_{g}^{\text {air }}$ & $\mathrm{m}^{2} \mathrm{~s}^{-1}$ & $5.0 \times 10^{-6}$ \\
Water diffusion coefficient & $D_{L}^{\text {water }}$ & $\mathrm{m}^{2} \mathrm{~s}^{-1}$ & $5.0 \times 10^{-10}$ \\
\hline & & &
\end{tabular}

are $7.0 \times 10^{5}$ and $1.0 \times 10^{5}$ for in-cloud and below-cloud scavenging, respectively. In-cloud scavenging is more efficient due to the higher density of water droplets in clouds than below clouds.

\subsubsection{Chemical reactions in the atmosphere}

Reaction with $\mathrm{OH}$ radicals is assumed to be the most important degradation of $\alpha-\mathrm{HCH}$ in the atmosphere (Atkinson et al., 1999). The degradation rate depends on temperature and $\mathrm{OH}$ concentration in air as studied by Brubaker and Hites (1998). However, as an approximation a first order degradation rate is calculated in the model using an estimated mean residence time in the atmosphere due to reactions with $\mathrm{OH}$ radicals of $k_{\text {air }}=1 /(118$ days) (Mackay et al., 2000). This value is in agreement with an average atmospheric lifetime of 120 days calculated from the reaction rates measured by Brubaker and Hites (1998). The degradation rate is applied for the whole model domain and is not seasonal dependent. A transformation of $\gamma-\mathrm{HCH}$ into $\alpha-\mathrm{HCH}$ by $\mathrm{UV}$ radiation has been speculated (Pacyna and Oehme, 1988), but is not taken into account in the model since no direct observation has been made of this reaction in the environment.

\subsection{Surface compartments and air-surface exchange}

A description of the air-surface exchange processes is important when modelling the environmental fate of POPs to account for the multi-hop transport. A soil module and an ocean module are therefore included in DEHM-POP. The parameterisation of the exchange processes between air and surface compartments is based on a zonally averaged multicompartment model (Strand and Hov, 1996).

\subsubsection{The soil module}

The land covered surface in the model consists of a $0.15 \mathrm{~m}$ thick soil layer containing a mixture of soil, air and water in fractions kept constant with time. The soil layer is assumed to have the standard properties suggested by Jury et 


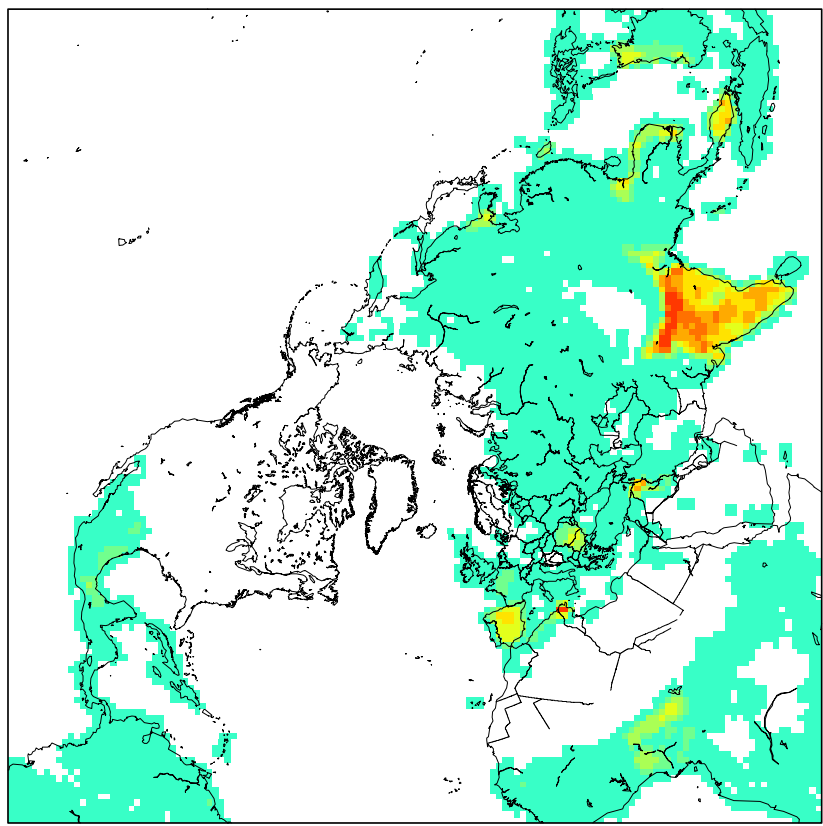

tonnes $\alpha-\mathrm{HCH} /$ year

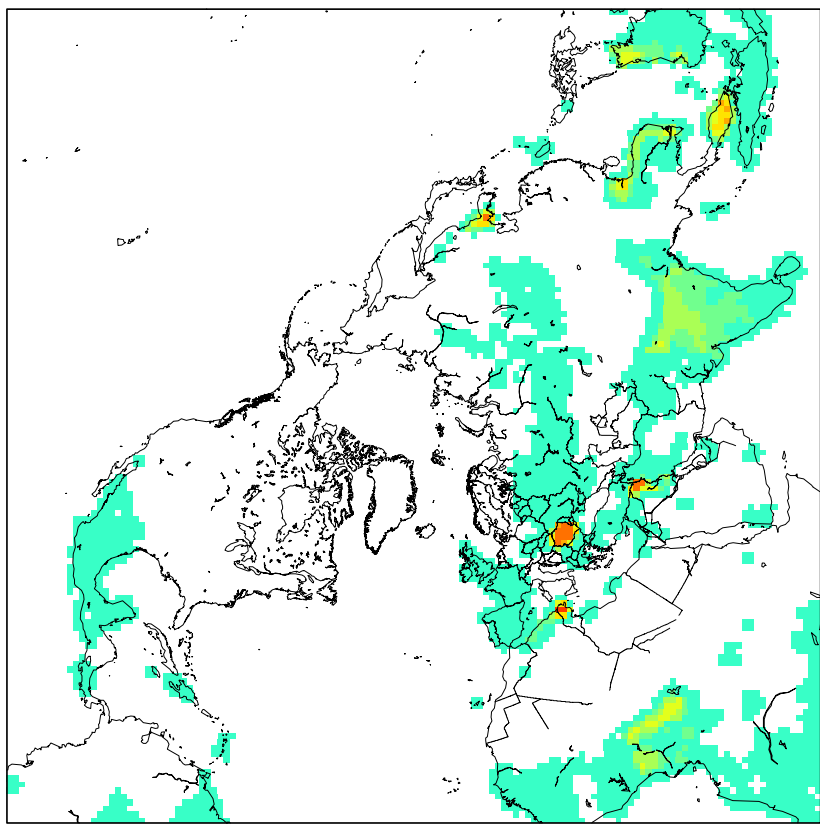

tonnes $\alpha-\mathrm{HCH} /$ year

Fig. 2. Emissions of $\alpha$-HCH for 1990 (left) and 2000 (right) (Li et al., 2000). The data are redistributed to the DEHM-POP model grid. Note the different colour scales.

al. (1983) that are listed in Table 1. The change in $\alpha-\mathrm{HCH}$ concentration in soil, $C_{s}$, with time is expressed by:

$\frac{\partial C_{s}}{\partial t}=\frac{1}{z_{s}}\left(F_{\text {exc, soil }}+F_{\text {wet }}-F_{\text {run-through }}\right)-k_{\text {soil }} C_{S}$,

where $z_{s}$ is the soil depth, $F_{\text {exc,soil }}$ is the air-soil gas exchange flux, $F_{\text {wet }}$ is the wet deposition, $F_{\text {run-through }}$ is the amount of chemical running out with the excess water through the bottom of the soil layer, and $k_{\text {soil }}$ is the degradation rate in soil.

Two additional fluxes are included in the original air-soil exchange process description: Application input and flux out of the soil due to evaporation of water (Strand and Hov, 1996). The amount of $\alpha-\mathrm{HCH}$ applied to the soil is taken into account when emissions to air are calculated and it is therefore disregarded in this context. The evaporation of water is omitted since data on the latent heat flux were not extracted from the meteorological model driving DEHM-POP.

The air-soil gas exchange flux is given by:

$F_{\text {exc, soil }}=v_{s}\left(C_{a}-\frac{C_{s}}{K_{\mathrm{sa}}}\right)$, where $v_{s}$ is the exchange velocity, and $K_{\mathrm{sa}}$ is the partitioning coefficient between soil and air in the soil. The exchange velocity is given by (Strand and Hov, 1996):

$v_{s}=\frac{\left(D_{G}^{\mathrm{air}} a^{10 / 3}+D_{L}^{\mathrm{water}} l^{10 / 3} H\right)(1-l-a)^{-2}}{z_{s} / 2}$,

where $D_{G}^{\text {air }}$ is the air diffusion coefficient, $D_{L}^{\text {water }}$ is the liquid diffusion coefficient, $l$ and $a$ is the water and air fractions in soil, respectively, and $H$ is the dimensionless Henry's law constant (Strand and Hov, 1996). Partitioning between soil and air in the soil is given by:

$K_{\mathrm{sa}}=\rho_{s} f_{\mathrm{oc}} K_{\mathrm{oc}} H+l+a$,

where $\rho_{s}$ is the soil density, $f_{o c}$ is the organic carbon fraction, and $K_{\mathrm{oc}}$ is the organic carbon partitioning coefficient taken to be: $K_{\mathrm{oc}}=1.3 \mathrm{~m}^{3} \mathrm{~kg}^{-1}$ (Strand and Hov, 1996). The dimensionless Henry's law constant, $H$, is temperature dependent and calculated using the equation:

$H=R T \exp \left(\frac{2.303 m}{T}-2.303 b\right)$,

where $R$ is the molar gas constant, $T$ is the temperature and $m=2810$ and $b=9.31$ are empirical constants determined for distilled water (Kucklick et al., 1991). 
The excess run-through is calculated by:

$F_{\text {run-through }}=F_{\text {excess }} C_{s} \frac{H}{K_{\mathrm{sa}}}$,

where $F_{\text {excess }}$ is the flux of excess water, which in the model is equal to the precipitation rate because the water content in the soil layer is kept constant and water evaporation is omitted.

$\alpha-\mathrm{HCH}$ is subject to biodegradation in soil. This process is not well quantified and the degradation rate in soil is estimated to be: $k_{\text {soil }}=1 /(1$ year) (Strand and Hov, 1996). This value is generally higher than degradation rates used in other models. A half-life in soil of 120 days at $20^{\circ} \mathrm{C}$, increasing with decreasing temperatures, is used by Wania et al. (1999) and Breivik and Wainia (2002). Degradation rates of $1 /(3$ months $)-1 /(4$ months $)$ are used for the temperature range $270-301 \mathrm{~K}$ by Scheringer at al. (2000).

\subsubsection{The ocean water module}

The ocean is assumed to be a $75 \mathrm{~m}$ deep well mixed surface ocean compartment. The deep ocean, sediments and sea ice are not taken into account in the model.

The $\alpha-\mathrm{HCH}$ concentration in the ocean, $C_{o}$, changes with time:

$\frac{\partial C_{o}}{\partial t}=\frac{1}{z_{o}}\left(F_{\text {exc, ocean }}+F_{\text {wet }}\right)-k_{\text {ocean }} C_{o}$,

where $z_{o}$ is the depth of the ocean compartment, $k_{\text {ocean }}$ is the loss rate in the surface ocean compartment, and $F_{\text {exc,ocean }}$ is the air-ocean gas exchange flux given by:

$F_{\text {exc,ocean }}=v_{o}\left(C_{a}-\frac{C_{o}}{H}\right)$,

where $v_{o}$ is the exchange velocity calculated using the two layer resistance method. $v_{o}$ is increasing with increasing wind speed.

The Henry's law constant is determined as in Eq. (7) but with values for the empirical constants: $m=2969$ and $b=9.88$ determined for artificial ocean water (Kucklick et al., 1991).

Apart from re-volatilisation, $\alpha-\mathrm{HCH}$ is lost from the surface compartment by hydrolysis, biological degradation and particle settling. None of these processes is well quantified, and a simple degradation rate of $k_{\text {ocean }}=1 /(10$ years $)$ is used (Strand and Hov, 1996). This value is generally higher than estimates used in other models. A half-life of 4 months for ocean water and 3 years for fresh water is used by Wania et al. (1999). Breivik and Wainia (2002) use a half-life of 1 year for both ocean and fresh water. Degradation rates of $1 /(5.4$ years $)$ to $1 /(1.8$ months $)$ is used for the temperature range $270-301 \mathrm{~K}$ by Scheringer at al. (2000).

\subsection{Model input}

Meteorological data and emissions are used as input to the model simulations. Initial concentrations in the three me-
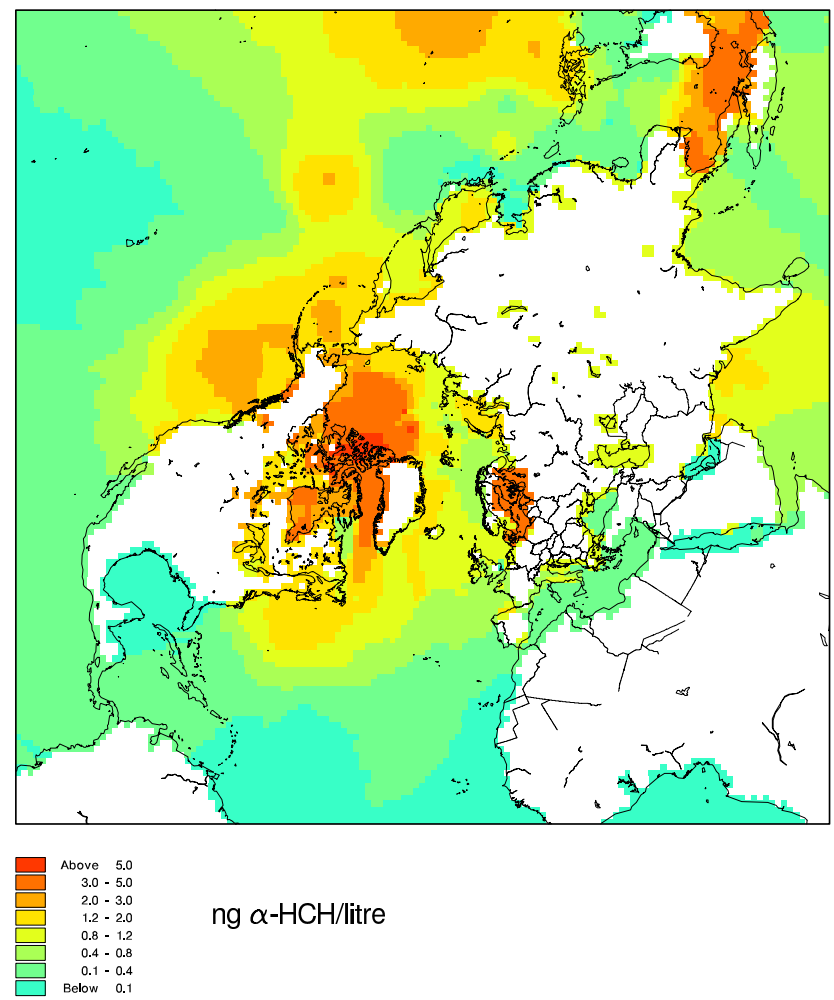

Fig. 3. Initial $\alpha-\mathrm{HCH}$ concentration in ocean water derived from an inter- and extra-polation of measurements from the late 1980s and early 1990s.

dia are also considered as input, since the usage of $\alpha-\mathrm{HCH}$ started more than 40 years before the modelling period.

\subsubsection{Meteorological data}

DEHM-POP is driven by meteorological data from the numerical weather prediction model MM5v2 (Grell et al., 1995). This model supplies temperature, wind velocity, and humidity data in each DEHM-POP grid cell for the years 1991-1998 with a time resolution of $3 \mathrm{~h}$. It uses the global meteorological TOGA data set from the European Centre for Medium Range Weather Forecasts on a $2.5^{\circ} \times 2.5^{\circ}$ grid with a time resolution of $12 \mathrm{~h}$ as input.

\subsubsection{Emission data}

As emission input we use data on global $\alpha$-HCH emissions in 1990 and 2000 distributed on a $1^{\circ} \times 1^{\circ}$ grid (Li et al., 2000). The emissions for each year are calculated by taking usage from that year as well as volatilisation from previous years usage into account (Li et al., 2000). The emissions have been redistributed to the DEHM-POP model grid (Fig. 2). 

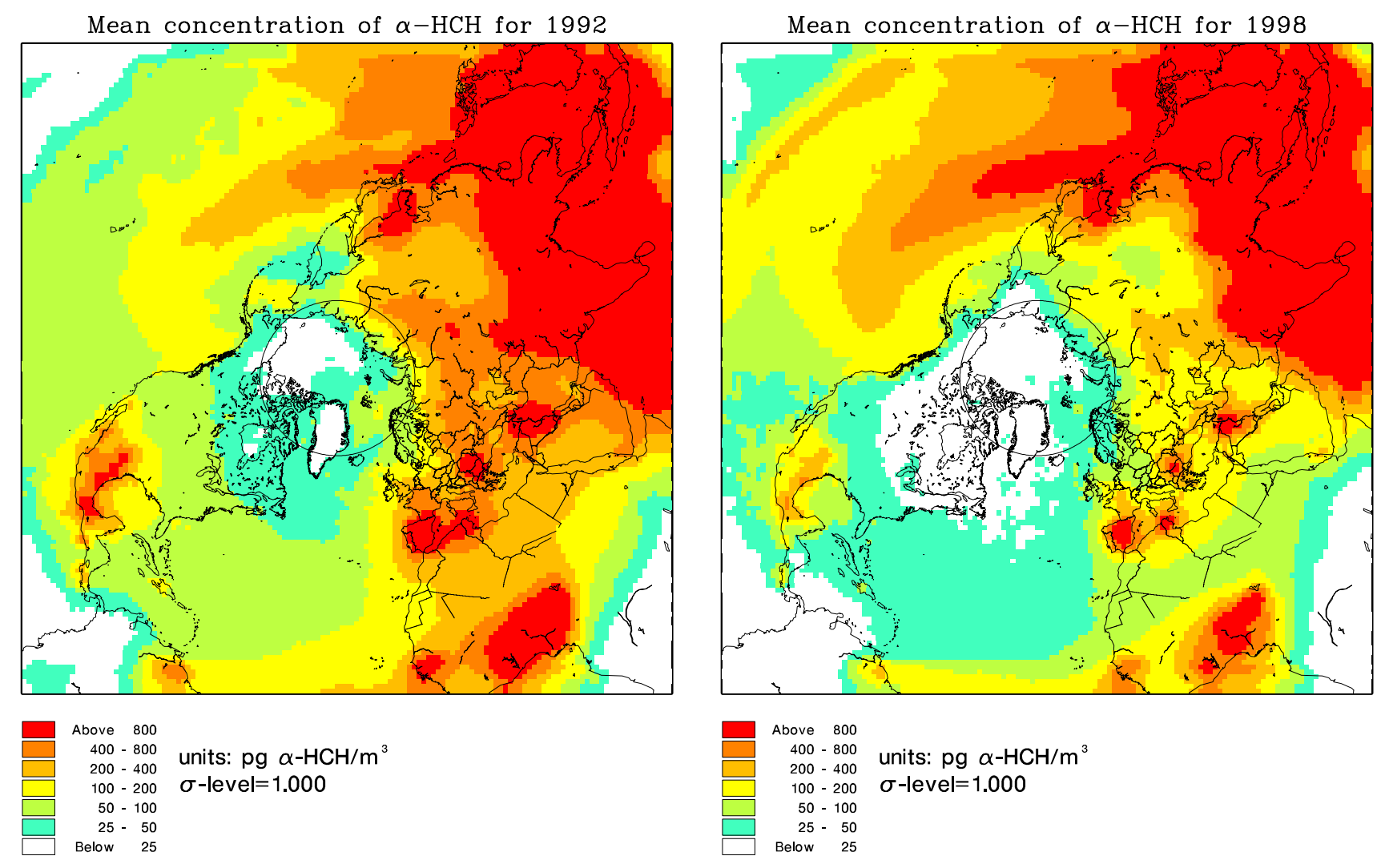

Fig. 4. Mean concentrations of $\alpha-\mathrm{HCH}$ in the lowermost atmospheric layer for the years 1992 (left) and 1998 (right).

Emissions for the years 1991-1998 have been obtained by assuming a linear development of the emissions between 1990 and 2000 in each grid cell. The emissions for each year have been distributed evenly throughout the year. Emissions are mixed up to a height of $800 \mathrm{~m}$, a typical extension of the planetary boundary layer.

\subsubsection{Initial concentrations}

Most of the estimated 9.4 million tonnes Technical HCH was used before the start of the modelled period. Due to the great persistence of the compound some of it is still found in the environment, especially in the ocean since $\alpha-\mathrm{HCH}$ is one of the most water soluble POPs. This can act as a source to the atmosphere by re-volatilisation, which has been observed in the Bering and Chukchi Seas (Jantunen and Bidleman, 1995). A set of $\alpha-\mathrm{HCH}$ measurements from the late 1980s and early 1990s collected from the literature (Terry Bidleman, personal communication) was plotted in the DEHM-POP grid. Values in all DEHM-POP grid cells were inter- and extrapolated from these (Fig. 3). This is used as initial condition for the model simulation. Measurements from between 1987 and 1996 are used to ensure a reasonable coverage of the world's oceans and as large a number of points for the interpolation as possible. In grid points with more than one measurement, the average value of the measurements was used.
No initial concentration in soil is used in the model simulation. Since emissions from residues in agricultural soil from previous years usage is taken into account in the emission data, only the re-emission from previous deposition of chemicals to the soil is not accounted for.

The mixing time in the atmosphere is short and atmospheric concentrations rapidly disperse through the model domain. No initial concentration in the atmosphere is therefore used in the model simulation. To minimise the effect of this assumption, data from January 1991 is omitted in the model evaluation.

\section{Results}

The model was run for the years 1991-1998. The mean concentration in the lowermost atmospheric layer for the years 1992 and 1998 is seen in Fig. 4. Air concentrations are generally high over areas with emissions such as India, Southeast Asia, Southern Europe and Mexico, but significant concentrations are also seen in air over areas without primary emissions such as the Atlantic and Pacific Oceans and the Arctic. There is generally a decrease in air concentrations from 1992 to 1998. However, in some areas over the Pacific Ocean the air concentrations increase. 
Table 2. Years of sampling, number, typical deployment time and sampling frequency of the measurements, and mean and range of measurements and model results for each of the studied stations (Aas et al., 2003; Berg et al., 2001). ${ }^{1}$ Measurements at Lista have been made once a week but only monthly mean values were available for this study.

\begin{tabular}{lllllll}
\hline Station & $\begin{array}{l}\text { Years of } \\
\text { sampling }\end{array}$ & $\begin{array}{l}\text { Number of } \\
\text { measurements }\end{array}$ & $\begin{array}{l}\text { Average } \\
\text { develpment } \\
\text { time (days) }\end{array}$ & $\begin{array}{l}\text { Average } \\
\text { sampling } \\
\text { frequency }\end{array}$ & $\begin{array}{l}\text { Measurements } \\
\text { Mean and range } \\
\left(\text { pgm }^{-3}\right)\end{array}$ & $\begin{array}{l}\text { Model results } \\
\text { Mean and range } \\
\left(\mathrm{pgm}^{-3}\right)\end{array}$ \\
\hline Alert & $1992-1998$ & 303 & 7 & $1 /$ week & $54.4(0.1-310.7)$ & $28.8(2.6-84.2)$ \\
Tagish & $1992-1994$ & 80 & 7 & $1 /$ week & $70.4(23.6-160.0)$ & $42.1(16.9-86.3)$ \\
Spitzbergen & $1993-1998$ & 303 & 2 & $1 /$ week & $58.9(0.1-203.1)$ & $49.5(5.5-153.8)$ \\
Dunai Island & 1993 & 33 & 7 & $1 /$ week & $40.0(0.6-77)$ & $60.5(9.8-124.9)$ \\
Lista & $1991-1998$ & 95 & 1 & $1 /$ week & $66.6(20.8-170)$ & $96.1(39.6-197.4)$ \\
Rörvik & $1994-1998$ & 56 & 7 & $1 /$ month & $24.2(2-63)$ & $65.4(15.8-191.4)$ \\
Aspvreten & $1995-1998$ & 40 & 7 & $1 /$ month & $55.7(20-161)$ & $73.1(18.6-190.3)$ \\
Pallas & $1996-1998$ & 36 & 7 & $1 /$ month & $23.2(3-40)$ & $37.6(8.4-88.1)$ \\
Storhófdi & $1995-1998$ & 103 & 14 & $2 /$ month & $16.7(3.7-55.9)$ & $30.4(11.7-57.8)$ \\
\hline
\end{tabular}

3.1 Model evaluation

Monitoring programs with regular measurements of atmospheric POPs concentrations have been established since the beginning of the 1990s by deployment of active air samplers at different sites. The time span and the temporal resolution of the measurements are very variable at the different stations (Table 2). To evaluate the model results, measurements from 9 stations in the Northern Hemisphere are obtained from EMEP (Aas et al., 2003; Berg et al., 2001). The location of the stations is plotted in Fig. 5. Only four stations conduct continuous measurements: Alert, Tagish, Dunai Island, and Storhófdi. At the other stations measurements are made only $20-30 \%$ of the time.

Daily averaged concentrations from the lowermost atmospheric layer of the model are extracted at each measurement site. A clear seasonal pattern with higher concentrations during summer than winter is found in the daily averaged $\alpha$ $\mathrm{HCH}$ concentrations in the model at all stations and most clearly for the two high Arctic stations at Alert and Spitzbergen (not shown). At the more southerly stations the amplitude of the seasonal signal is lower and the seasonal pattern is perturbed by short-term spikes mainly drring summer (not shown). When air samples are taken over several days, the model results are averaged over the deployment time of the air sampler to make a direct comparison of the model results with individual measurements possible. Measurements at Lista are made once a week but only monthly averaged values were available for this study. These were compared to the average concentration for the whole month from the model, because the date of the individual measurements were not known. Concentrations in soil and ocean water are not evaluated.

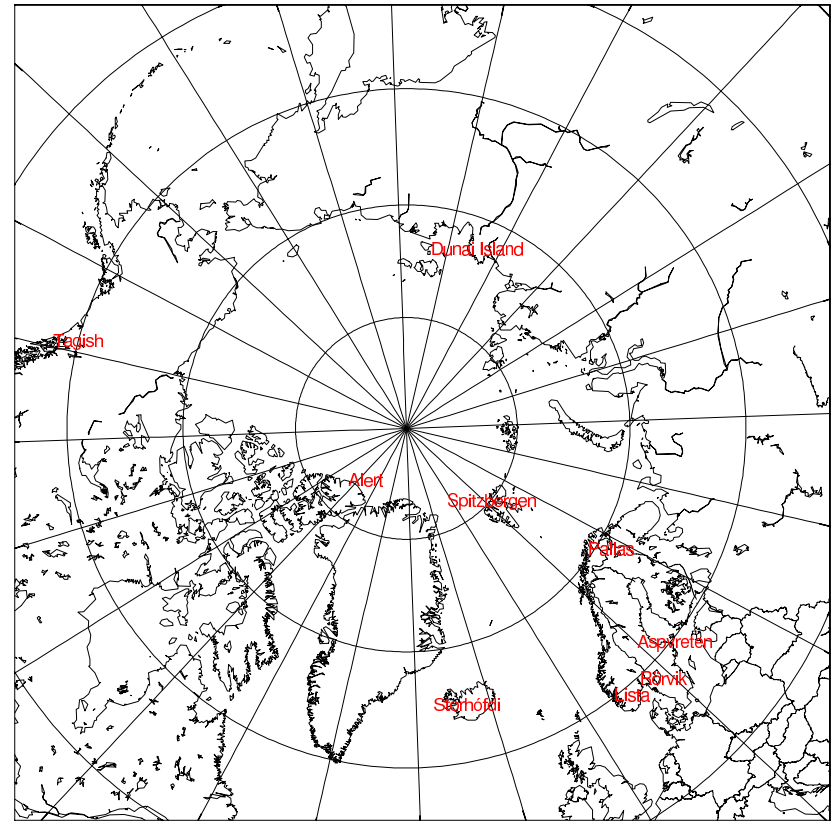

Fig. 5. Location of the 9 measurement stations used in the model evaluation.

\subsubsection{Annual averaged air concentrations}

The average and range for all measurements and corresponding model results are calculated for each station (Table 2). Annual averages are also calculated and compared (Fig. 6). The predicted averaged concentrations are within a factor 3 of the measurements at all stations and for most stations within a factor 2 or less. The averaged concentrations are consistently underestimated by the model at the three stations 
Annual Average air concentrations

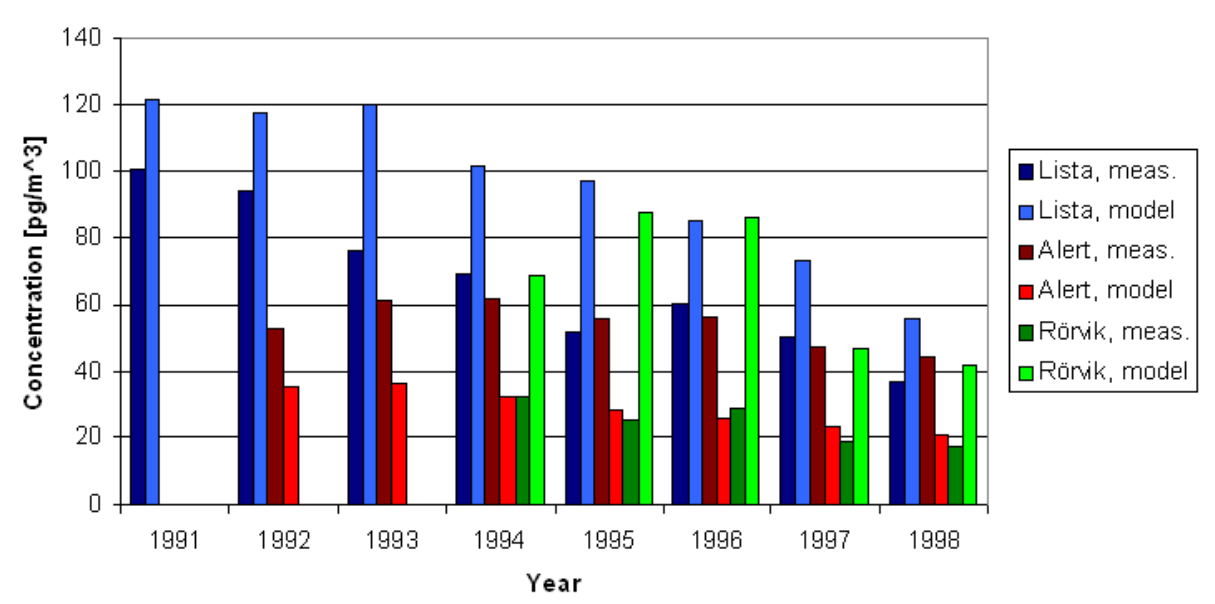

Fig. 6. Three examples of the annual averaged concentration of $\alpha-\mathrm{HCH}$ in the lowermost atmospheric layer: Lista (blue) Alert (red) and Rörvik (green). Measurements are shown in dark colours and model results in light colours.

Alert, Spitzbergen and Tagish but consistently overestimated at all other stations. Except for some very low measured values, the range of the model predictions is within a factor 4 of the range of measurements (Table 2).

\subsubsection{Evaluation against individual measurements}

The model results are also compared directly with individual measurements. When the model results are averaged over the days of each individual measurement, the seasonal pattern seen in the daily averaged model concentrations is averaged out at all stations but Alert, Spitzbergen and Lista (not shown). Measured $\alpha-\mathrm{HCH}$ concentrations are plotted against model calculations in scatter plots and correlation is tested with a t-test. No statistically significant correlation is found except at Rörvik, significant within a $1 \%$ significance level, and at Lista, significant within a $0.1 \%$ significance level (Fig. 7).

There are negative trends in both measured and modelled concentrations over the years 1991-1998 at Lista that are very similar; the measurements decrease with $8.4 \mathrm{pgm}^{-3}$ per year, while the model results decrease by $9.1 \mathrm{pgm}^{-3}$ per year on average (Fig. 8).

\section{Discussion}

The decreased air concentrations from 1992 to 1998 predicted by the model (see Fig. 4) reflect the reduced emissions in this period. Higher $\alpha-\mathrm{HCH}$ concentrations over the Bering Sea than over the surrounding seas in the beginning of the model simulation indicate a re-volatilisation from the ocean to the air, which has also been observed in the beginning of the 1990s (Jantunen and Bidleman, 1995). In 1998 there is a higher $\alpha-\mathrm{HCH}$ concentrations in air over some parts of the Pacific Ocean than in 1992. This can be interpreted as a closer equilibrium between air and ocean water towards the end of the model simulation, which will lead to a decreased deposition to the ocean and hence a potential for higher concentrations in the air.

The spikes found in the daily averaged model data can be interpreted as individual transport episodes from areas with primary emissions. More spikes are therefore found at the low latitude stations closer to source areas than at the high latitude stations.

The seasonal pattern, with higher concentrations drring summer than drring winter found in the daily averaged model results, indicates that temperature dependent re-volatilisation from the surface contributes significantly to the atmospheric concentrations. Another indication of this is the trend in air concentrations seen at Lista (see Fig. 8), which decrease much less than the emissions over the modelled period (see Fig. 2). Higher amplitudes in the seasonal pattern at the high Arctic stations are probably due to higher temperature amplitudes here. Another factor influencing the air concentrations at the high Arctic sites is the omission of sea ice in the model, which leads to higher re-volatilisation from the oceans. Sea ice acts as a lid on the Arctic Ocean reducing the air-ocean exchange greatly.

Observations of $\alpha-\mathrm{HCH}$ in air at the high Arctic stations indicate a bi-modal pattern with peak concentrations in spring and autumn (Hung et al., 2002). Different mechanisms have been suggested to explain this pattern, e.g. a filter effect of the vegetation, removing the chemicals in air from contaminated areas before it reaches the Arctic (Hung et al., 2002). Other factors influencing the air concentration pattern could be re-volatilisation from the snowpack and a change in type of precipitation (Halsall, 2004). Neither of these processes is, at present, taken into account in the model 
Alpha-HCH in air 1993-1998: Spitzbergen, Svalbard

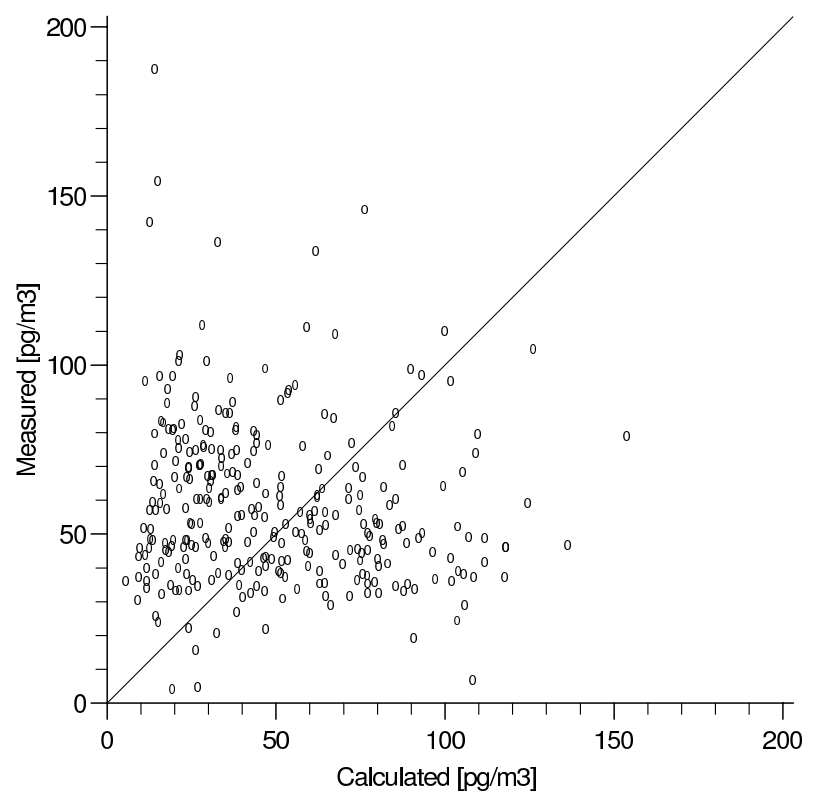

$\mathrm{N}=303$, means: calculated $=49.52$, measured $=58.89$ Standard deviations: calculated $=29.87$, measured $=25.75$ correlation $=-0.07$, test $($ Hypotesis: correlation $=0): t=-1.19$

Alpha-HCH in air 1994-1998: Rörvik, Sweden

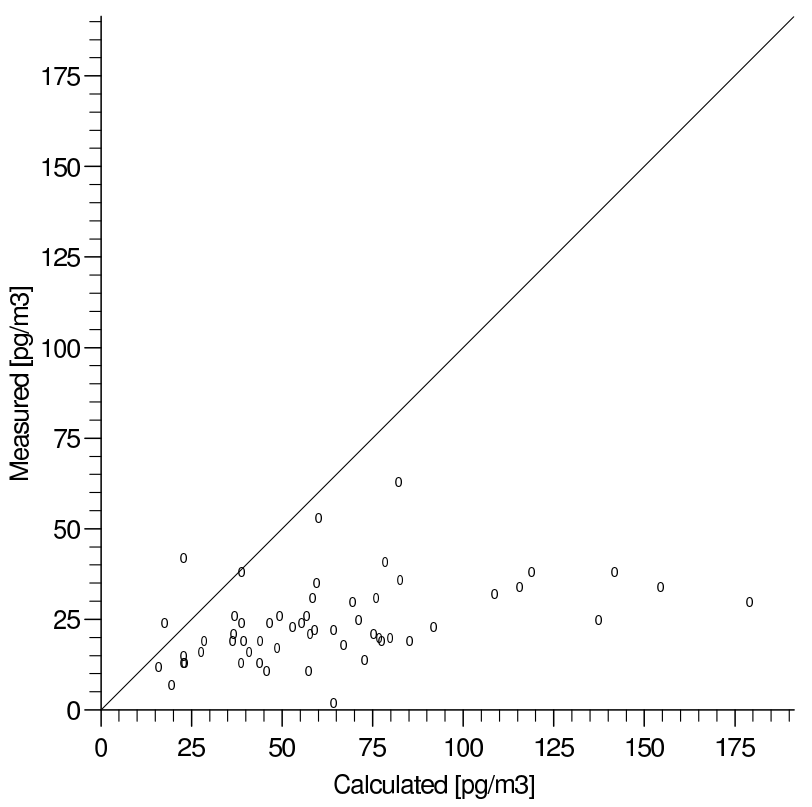

$\mathrm{N}=56$, means: calculated $=65.43$, measured $=24.18$ Standard deviations: calculated $=38.55$, measured $=10.88$ correlation $=0.37$, test $($ Hypotesis: correlation $=0): t=2.96$
Alpha-HCH in air 1991-1998: Lista, Norway

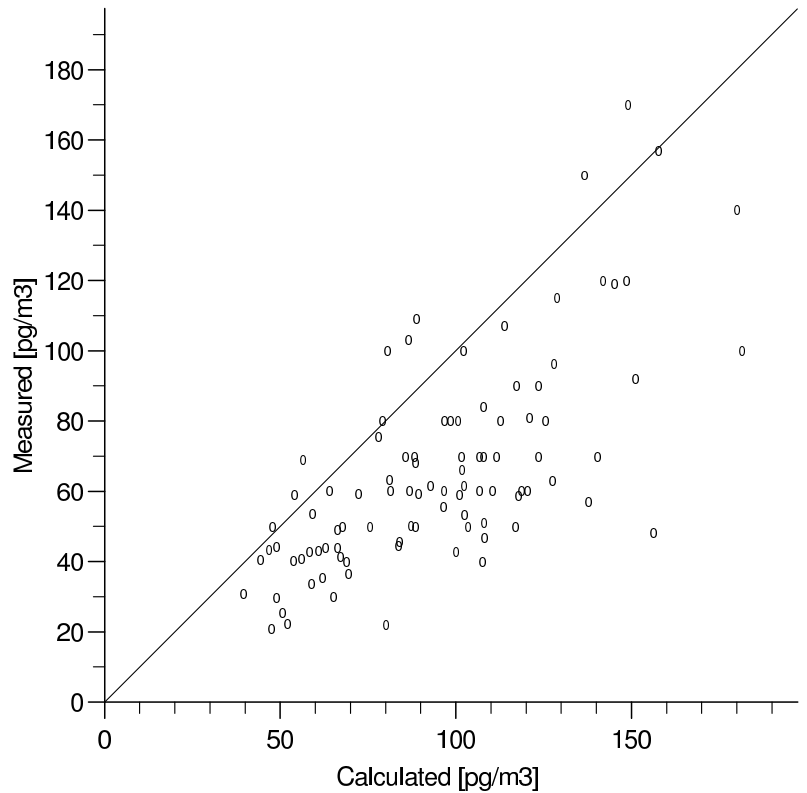

$\mathrm{N}=$ 96, means: calculated $=96.09$, measured $=66.63$ Standard deviations: calculated $=33.45$, measured $=29.81$ correlation $=0.71$, test $($ Hypotesis: correlation $=0): t=9.88$

Alpha-HCH in air 1995-1998: Aspvreten, Sweden

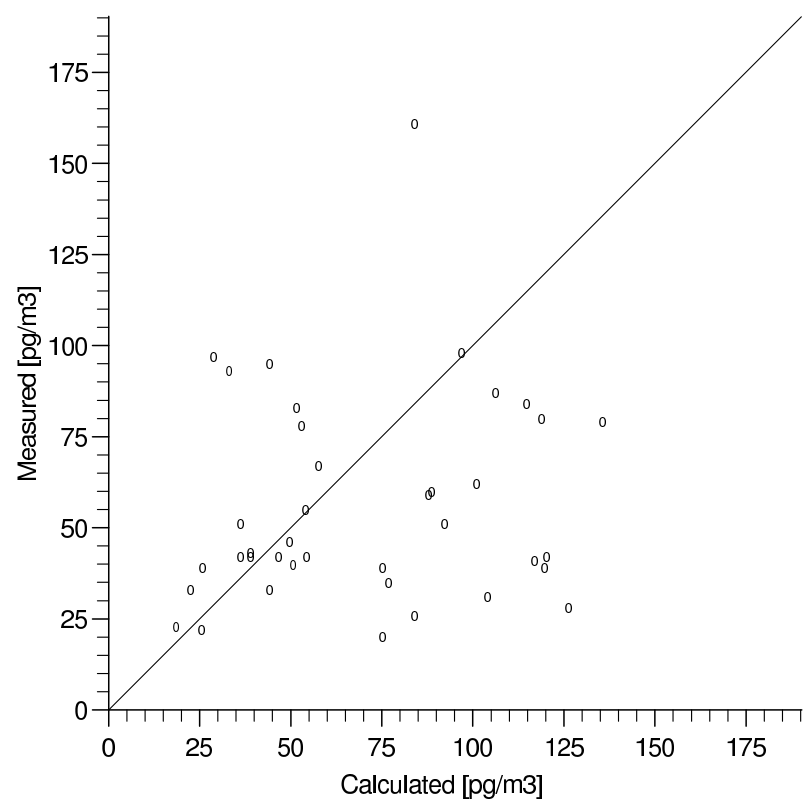

$\mathrm{N}=40$, means: calculated $=73.14$, measured $=55.67$ Standard deviations: calculated $=38.41$, measured $=28.23$ correlation $=0.08$, test $($ Hypotesis: correlation $=0): t=0.49$

Fig. 7. Four examples of the measured $\alpha-\mathrm{HCH}$ concentrations in the lowermost atmospheric layer plottet against predicted concentrations: Spitzbergen (upper left), Lista (upper right), Rörvik (lower left) and Aspvreten (lower right). The results from all other stations are similar to Spitsbergen and Aspvreten. 


\section{Monthly average $\alpha-\mathrm{HCH}$ concentrations at Lista, Norway}

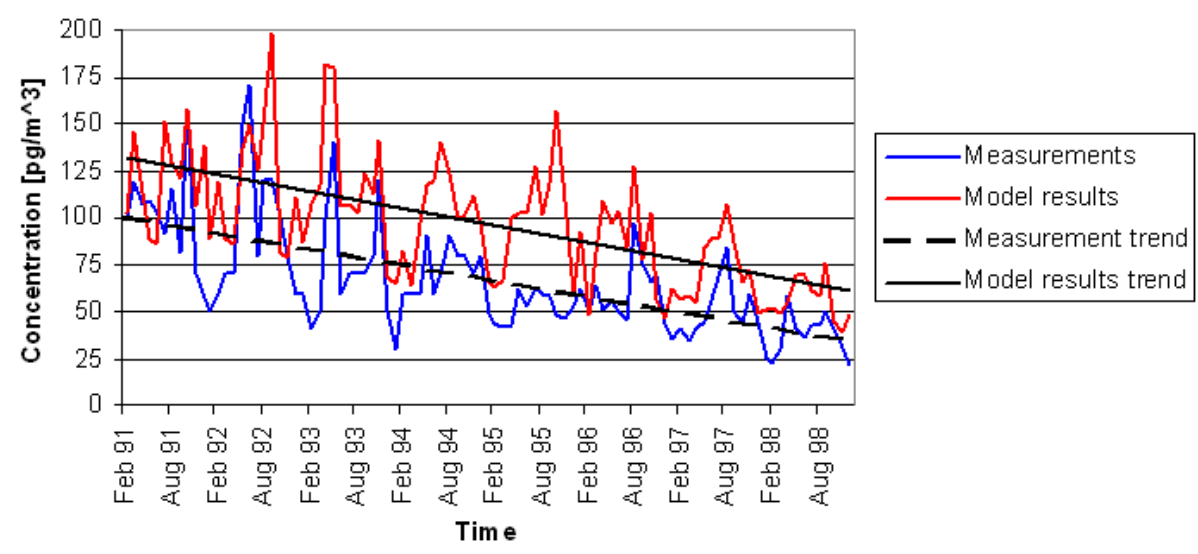

Fig. 8. Monthly averaged $\alpha-\mathrm{HCH}$ concentrations at Lista for measurements (blue) and model results (red). Black lines show the decreasing trend in concentrations for the measurements (dashed) and model results (solid).

with the very simple surface parameterisation. This offers an explanation of the deviation of the model results from the observed pattern. There are further indications that surface characteristics not described with the simple surface parameterisation in the model, e.g. vegetation, influence the observed values but not the model results. The lack of correlation between individual measurements and model results is one indication (see Fig. 7). Another indication of this is the difference between the two Swedish stations Rörvik and Aspvreten, which are separated by only a few grid cells. There is a high correlation of the daily averaged air concentrations in the model between the two stations, but the similar evaluation against measurements is very different. Almost all measured concentrations are underestimated at Rörvik and there is a low but statistically significant correlation between measurements and model results, while the data show more scatter at Aspvreten (Fig. 7).

Contrary to the other stations, the correlation between measurements and model results at Lista is evident (see Figs. 7 and 8). Although the model results are not compared directly with measurements at Lista but with average values of 4-5 measurements for each month, the correlation is not believed to be an artifact of the data treatment. The location of the station, at the southern tip of Norway, probably influences the correlation between measurements and model results. Back-trajectory calculations indicate that the air measured at Lista originate from the nearby North Sea about $2 / 3$ of the time (Haugen et al., 1998). In this case, the simple surface parameterisation used in the model apparently is sufficient to capture the air-surface exchange proceses.

A seasonal pattern is not noticed in $\alpha-\mathrm{HCH}$ measurements from Lista, and the concentrations measured between 1991 and 1995 are suggested to arise from advection into the area (Haugen et al., 1998). However, seasonal patterns may not be captured by the measurements due to non-continuous de- ployment periods at most stations. An indication of this is found for the model results where the seasonal pattern is no longer apparent for most stations when the results are averaged over the periods of the individual measurements (not shown). Furthermore, when the monthly averaged measurements from 1991-1998 at Lista are averaged for each month there do appear to be higher concentrations in the summer months than in the winter months as is found in the model results (Fig. 9).

The emission data is also a source of uncertainty in the model results. The assumption of evenly distributed emissions throughout the year can also contribute to the deviations between measurements and model results. The usage of $\mathrm{HCH}$ is closely linked to the crop season since it is an insecticide. However, different usage patterns in different parts of the world complicate estimation of emission factors, and, at present, emission data with higher temporal resolution are not available. Another uncertainty induced by the emission input arises from the estimation of the annual emissions for the years 1991-1998 by linear interpolation of the 1990 and 2000 emissions. This approach fails to account for sudden decrease in emissions from one year to another due to a ban on usage of the compound. We chose to use this approach, since no emission estimates for the years were available.

\subsection{Comparison with other model results}

Three different box models were used previously to study the global fate of $\alpha-\mathrm{HCH}$. Two models are zonally averaged models with 6 and 10 zonaly averaged regions, respectively (Strand and Hov, 1996; Wania et al., 1999). The third model is divided into 25 zones following both climatic and continental or political borders (Toose et al., 2004). It is difficult to compare the results from these models directly with the DEHM-POP results because of their low spatial resolution. 


\section{Average concentration for each month for the years 1991-1998}

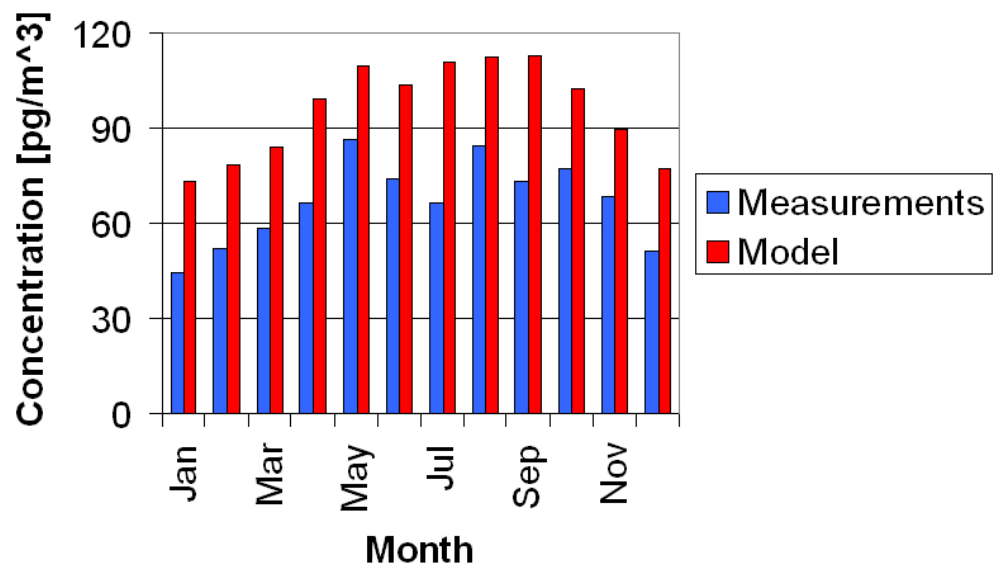

Fig. 9. Average $\alpha$-HCH concentration for each month for the years 1991-1998 at Lista, Norway. Measurements are shown in blue and model results in red.

The results from the Strand and Hov model are given as annual average concentrations for the year 1985 and the air concentrations are higher than predicted by DEHM-POP (Strand and Hov, 1996). This can be explained by higher emissions for the years before 1990 .

The other two models were run for a 50 year period. The Wania et al. model predicts generally a factor 2-3 higher concentrations than DEHM-POP in the 1990s (Wania et al., 1999). Results from the Toose et al. model agree well with DEHM-POP model results for the European and Arctic regions, but are approximately a factor 10 lower for Arctic Canada (Toose et al., 2004).

A regional scale model covering the Baltic Sea region based on the global distribution model of Wania et al. (1999) was used to study the environmental fate of $\alpha-\mathrm{HCH}$ for the years 1970-2000 (Breivik and Wainia, 2002). This model obtains very good predictions of both seasonal averaged and individual measured air concentrations at Lista and Rörvik for the 1980s and 1990s (Breivik and Wainia, 2002).

Overall, there is a fairly good agreement between DEHMPOP and the four box models despite the differences in spatial resolution and process description. However, it is important to note that the two types of models should not be seen as competitors but rather as complementing each other, as discussed by Wania (1999).

Only one atmospheric transport model using dynamical meteorological data as input was used to study the environmental fate of $\alpha-\mathrm{HCH}$ (Koziol and Pudykiewicz, 2001). The model is a global atmospheric transport model with a horizontal resolution of $2^{\circ} \times 2^{\circ}$ and 11 vertical layers, and it has been used to study the atmospheric transport of $\alpha-\mathrm{HCH}$ for the years 1993-1994 (Koziol and Pudykiewicz, 2001). A clear seasonal pattern with higher values drring summer than winter is also seen in the model results for the four studied stations: Alert, Spitzbergen, Dunai Island and Tagish (Koziol and Pudykiewicz, 2001). For the first three stations the concentrations predicted by the two models are of comparable magnitude, whereas for Tagish the Koziol and Pudykiewicz model predicts a factor 5-6 higher concentrations than DEHM-POP.

\section{Conclusions}

The Danish Eulerian Hemispheric Model was further developed to describe the atmospheric transport and environmental fate of persistent organic pollutants in the Northern Hemisphere. Two surface compartments and exchange processes between air and the surfaces were introduced in the model to account for the multi-hop transport of POPs.

The model was used to study the atmospheric transport and environmental fate of the insecticide $\alpha$ hexachlorocyclohexane for the years 1991-1998, and the results were evaluated against measurements. The model results are promissing. The annual averaged air concentration of $\alpha-\mathrm{HCH}$ is predicted within a factor 2-3 of measured concentrations in the model domain. These results are of equal or higher accuracy than results from previous models describing the environmental fate of $\alpha-\mathrm{HCH}$. The shorter-term averaged air concentration of $\alpha-\mathrm{HCH}$ is well predicted at two of the stations, however, at the other stations there is no correlation between individual measurements and model results. This is probably due to the simple description of the surface characteristics, where only two types of surfaces are included: soil and ocean water. There is thus a need for investigating the role of the omitted surface 
characteristics such as vegetation, snow, ocean currents, and sea ice on the fate of POPs. To study POPs in general there is also a need for describing the partitioning between the gas phase and the aerosol phase. We are currently developing the model further by considering these issues.

Acknowledgements. This project is partly funded by the Danish Research Training Council through the Copenhagen Global Change Initiative. Thanks to professor Terry Bidleman for supplying a collection of data on measured $\alpha-\mathrm{HCH}$ concentrations in ocean water and to Mr. Carsten Ambelas Skjøth for comments on the manuscript.

Edited by: O. Hertel

\section{References}

Aas, W., Solberg, S., Berg, T., Manø, S., and Yttri, K. E.: Monitoring of long rang transported air pollutants, Annual report for 2002. Kjeller, Norwegian Institute for Air Research, SFT Report 877/2003 NILU OR 23/2003, 2003.

AMAP, AMAP Assessment Report: Arctic Pollution Issues. Arctic Monitoring and Assessment Programme (AMAP), Oslo, Norway, xii+859, 1998.

Atkinson, R., Guicherit, R., Hites, R. A., Palm, W.-U., Seiber, J. N., and De Voogt, P.: Transformation of pesticides in the atmosphere: A state of the art, Water Air Soil Poll., 115, 219-243, 1999.

Berg, T., Hjellbrekke, A. G., and Larsen R.: Heavy metals and POPs within the EMEP region 1999, EMEP/CCC 9/2001, 2001.

Breivik, K. and Wania, F.: Evaluating a model of the historical behaviour of two hexachlorocyclohexanes in the Baltic Sea environment, Env. Sc. Techn., 36, 5, 1014-1023, 2002.

Brubaker, W. W. and Hites, R. A.: OH reaction kinetics of gasphase $\alpha$ - and $\gamma$-hexachlorocyclohexane and hexachlorobenzene, Env. Sc. Techn., 32, 6, 766-769, 1998.

Christensen, J. H.: The Danish Eulerian Hemispheric Model - a three-dimensional air pollution model used for the Arctic, Atmos. Env., 31, 4169-4191, 1997.

Christensen, J. H.: An overview of Modelling the Arctic mass budget of metals and sulphur: Emphasis on source apportionment of atmospheric burden and deposition, In: Modelling and sources: A workshop on Techniques and associated uncertainties in quantifying the origin and long-range transport of contaminants to the Arctic, Report and extended abstracts of the workshop, Bergen, 14-16 June 1999, AMAP report 99:4. see also urlhttp://www.amap.no/, 1999.

Frohn, L. M., Christensen, J. H., and Brandt, J.: Development of a high-resolution nested air pollution model - the numerical approach, J. Comp. Phys., 179, 68-94, 2002.

Geels C., Doney, S., Dargaville, R., Brandt, J., and Christensen, J. H.: Investigating the sources of synoptic variability in atmospheric $\mathrm{CO}_{2}$ measurements over the Northern Hemisphere continents - a regional model study, Tellus B, 56B, 35-50, 2004.

Grell, G. A., Dudhia, J., and Stauffer, D. R.: A descripition of the fifth-generation Penn State NCAR Mesoscale Model (MM5), NCAR/TN-398+STR, NCAR Technical Note, Mesoscale and Microscale Meteorology Division, National Center for Atmospheric Research, Boulder, Colorado, 122, 1995.
Halsall, C. J., Bailey, R., Stern, G. A., Barrie, L. A., Fellin, P., Muir, D. C. G., Rosenberg, B., Rovinsky, F. Ya., Kononov, E. Ya., and Pastukhov, B.: Multi-year observations of organohalogen pesticides in the Arctic atmosphere, Env. Poll., 102, 51-62, 1998.

Halsall, C. J.: Investigating the occurence of pesistent organic pollutants (POPs) in the Arctic: Their atmospheric behaviour and interaction with the seasonal snow pack, Env. Poll., 128, 1-2, 163-175, 2004.

Haugen, J.-E., Wania, F., Ritter, N., and Schlabach, M.: Hexachlorocyclohexanes in air in Southern Norway. Temporal variation, source allocation, and temperature dependence, Env. Sc. Techn., 32, 2, 217-224, 1998.

Hung, H., Halsall, C. J., Blanchard, P., Li, H. H., Fellin, P., Stern, G., and Rosenberg, B.: Temporal trends of organochlorine pesticides in the Canadian Arctic atmosphere, Env. Sc. Techn., 36, 5, 862-868, 2002.

Jantunen, L. M. and Bidleman, T. F.: Reversal of the air-water gas exchange direction of hexachlorocyclohexanes in the Bering and Chukchi Seas: 1993 versus 1988, Env. Sc. Techn., 29, 4, 10811089, 1995.

Jones, K. C. and de Voogt, P.: Persistent organic pollutants (POPs): State of the science, Env. Poll., 100, 209-221, 1999.

Jury, W. A., Spencer, W. F., and Farmer, W. J.: Behaviour assessment model for trace organics in soil: I. Model description, J. Env. Qual., 12, 558-564, 1983.

Koziol, A. S. and Pudykiewicz, J. A.: Global-scale environmental transport of persistent organic pollutants, Chemosphere, 45, 1181-1200, 2001.

Kucklick, J. R., Hinckley, D. A., and Bidleman, T. F.: Determination of Henry's law constants for hexachlorocyclohexanes in distilled water and artificial seawater as a function of temperature, Mar. Chem., 34, 197-209, 1991.

Li, Y.-F.: Global technical hexachlorocyclohexane usage and its contamination consequences in the environment: From 1948 to 1997, Sci. Total Environ., 232, 121-158, 1999.

Li, Y.-F., Scholtz, M. T., and van Heyst, B. J.: Global gridded emission inventories of $\alpha$-hexachlorocyclohexane, J. Geophys. Res., 102, D5, 6621-6632, 2000.

Li, Y.-F., Scholtz, M. T., and van Heyst, B. J.: Global gridded emission inventories of $\beta$-hexachlorocyclohexane, Env. Sc. Techn., 37, 16, 3493-3498, 2003.

Ma, J., Daggupaty, S., Harner, T., and Li, Y.-F.: Impacts of Lindane usage in the Canadian prairies on the Great Lakes ecosystem, 1. Coupled atmospheric transport model and modeled concentrations in air and soil, Env. Sc. Techn., 37, 17, 3774-3781, 2003.

Mackay, D., Shiu, W.-Y., and Ma, K.-C.: Physical-Chemical Properties and Environmental Fate Handbook. CD-ROM, Chapman \& Hall/CRnetBASE, London, 2000.

MacLoed, M., Woodfine, D. G., Mackay, D., McKone, T., Bennett, D., and Maddalena, R.: BETR North America: A regonally segmented multimedia contaminant fate model for North America, Env. Sc. Poll. Res., 8, 3, 156-163, 2001.

Malanichev, A., Mantseva, E., Shatalov, V., Strukov, B., and Vulykh, N.: Numerical evaluation of the PCB transport over the Northern Hemisphere, Env. Poll., 128, 1-2, 279-289, 2004.

Pacyna, J. M. and Oehme, M.: Long-range transport of some organic compounds to the Norwegian Arctic, Atmos. Env., 22, 2, 243-257, 1988. 
Prevedouros, K., MacLeod, M., Jones, K. C., and Sweetman, A. J.: Modelling the fate of persistent organic pollutants in Europe: parameterisation of a gridded distribution model, Env. Poll., 128, $1-2,251-261,2004$

Scheringer, M., Wegmann, F., Fenner, K., and Hungerbühler, K.: Investigation of the cold condensation of persistent organic pollutants with a global multimedia fate model, Env. Sc. Techn., 34, 9, 1842-1850, 2000.

Strand, A. and Hov, Ø.: A model strategy for the simulation of chlorinated hydrocarbon distributions in the global environment, Water Air Soil Poll., 86, 283-316, 1996.

Toose, L., Woodfine, M., MacLoed, M., Mackay, D., and Gouin, J.: BETR-World: A geographically explicit model of chemical fate: Application to transport of $\alpha-\mathrm{HCH}$ to the Arctic, Env. Poll., 128, 1-2, 223-240, 2004.

van Jaarsveld, J. A., van Pul, W. A. J., and de Leeuw, F. A. A. M.: Modelling transport and deposition of persistent organic pollutants in the European region, Atmos. Env., 31, 7, 1011-1024, 1997.
Wania, F. and Mackay, D.: Global fractionation and cold condensation of low volatility organochlorine compounds in polar regions, Ambio, 22, 1, 10-18, 1993.

Wania, F. and Mackay, D.: Tracking the distribution of persistent organic pollutants, Env. Sc. Techn., 30, 9, 390A-396A, 1996.

Wania, F.: Differences, Similarities, and Complementarity of Various Approaches to Modelling Persistent Organic Pollutant Distribution in the Environment, In: Proceedings of the WMO/ EMEP/UNEP Workshop on Modelling of Atmospheric Transport and Deposition of Persistent Organic Pollutants and Heavy Metals, 1, pp. 115-140, 1999.

Wania, F., Mackay, D., Li, Y.-F., Bidleman, T. F., and Strand, A.: Global chemical fate of $\alpha$-hexachlorocyclohexane, 1. Evaluation of a global distribution model, Env. Toxi. Chem., 18, 7, 13901399, 1999.

Willett, K. L., Ulrich, E. M., and Hites, R. A.: Differential toxicity and environmental fates of hexachlorocylohexane isomers, Env. Sc. Techn., 32, 15, 2197-2207, 1998. 